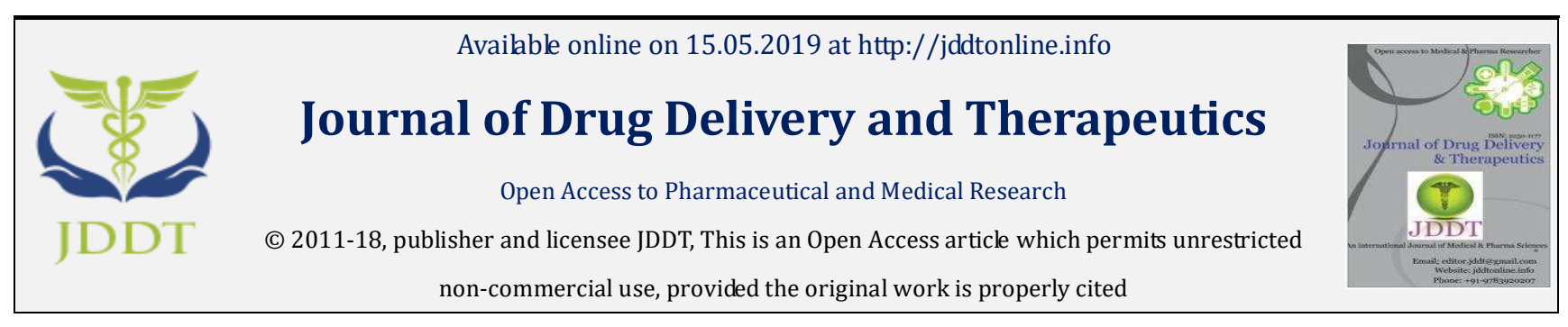

Open $\odot$ Access

Research Article

\title{
Intervention and Mechanism of Dexmedetomidine on A549 Cells Injured by
}

\section{Hypoxia/Reoxygenation}

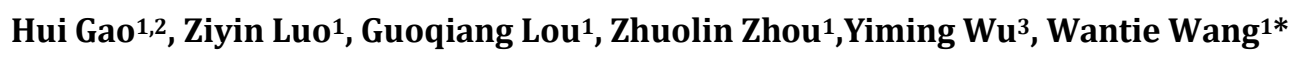 \\ ${ }^{1}$ Ischemia/Reperfusion Injury Research Institute of Wenzhou Medical University, Wenzhou, Zhejiang, 325035, China \\ 2 Huaihe Hospital of Henan University, Kaifeng, Henan, 475000, China \\ ${ }^{3}$ Division of Cardiovascular Medicine University of Iowa Carver College of Medicine Iowa City, American 50309
}

\begin{abstract}
Objective: To investigate the effect and mechanism of dexmedetomidine (DEX) on hypoxia /reoxygenation (H/R) injury of A549 cells.

Methods: A549 cells were cultured and randomly divided into four groups ( $\mathrm{n}=10$ ): Normoxic group;DEX group; $H / R$ injury group;H/R injury+DEX intervention group. Observe the morphological changes of cells; Cell viability was detected by cck-8 assay. TUNEL assay was used to detect apoptosis index (AI).Expressions of GRP78, CHOP, JNK, caspase-12, caspase-3 proteins and mRNA were detected by Western Blot and RT-PCR;Detect the activity of caspase-3.

Results: Compared with the H group, the OD value and AI value in the HD group were significantly up-regulated, apoptotic cells were significantly decreased, the expressions of CHOP, caspase-12, p-JNK and caspase-3 proteins and mRNA were significantly decreased, the GRP78 protein and mRNA increased, and the caspase-3 activity was significantly decreased, the differences were statistically significant $(P<0.01)$.

Conclusion: Dexmedetomidine has a protective effect on A549 cells after H/R injury, which may be related to its inhibition of apoptosis induced by excessive endoplasmic reticulm stress.
\end{abstract}

Keywords: Dexmedetomidine; Hypoxia/Reoxygenationinjury;Apoptosis;Endoplasmicreticulm stress.

Article Info: Received 18 March 2019; $\quad$ Review Completed 22 April 2019; Accepted 26 April 2019; $\quad$ Available online 15 May 2019

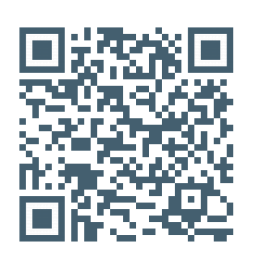

Cite this article as:

Gao H, Luo Z, Lou G, Zhou Z, Wu Y, Wang W, Intervention and Mechanism of Dexmedetomidine on A549 Cells Injured by

Hypoxia/ Reoxygenation, Journal of Drug Delivery and Therapeutics. 2019; 9(3):99-106

http://dx.doi.org/10.22270/jddt.v9i3.2607

*Address for Correspondence:

Wantie Wang, China, Zhejiang, Wenzhou, Wenzhou Medical College ischemia / reperfusion injury Institute, 325035, China.E-mail: wwt@wmu.edu.cn.

\section{INTRODUCTION}

With the booming and progress of lung transplantation, cardiopulmonary bypass and pulmonary surgery, lung ischemia / reperfusion injury (LIRI) is always a key factor for prognosis of heart and lung surgery. It is generally believed that apoptosis mechanism mediated by endoplasmic reticulum stress (ERS) involved in LIRI. LIRI resulted in the occurrence of ERS, activation of $\mathrm{C} / \mathrm{EBP}$ homologous protein (CHOP), caspase-12 (cysteinyl aspartate 
specific proteinase-12) and c-jun N-terminal kinase(JNK)-related apoptotic pathway, induce apoptosis and damage to lung tissue in vitro and vivo experiments of mouse [1-3].

Dexmedetomidine (DEX) is a highly selective $\alpha_{2}$ adrenergic receptor agonist. Relevant studies have shown that DEX can protect ischemia-reperfusion injury of the liver, lung, heart and other organs by reducing apoptosis, oxidative stress and inflammatory response, suppress sympathetic nerve excitement and other ways [4-6].The purpose of this study was to clarify the intervention and mechanism of DEX and the effect of ERS pathway on apoptosis of H/R cells. In order to provide sufficient experimental basis and theoretical basis for the clinical treatment of DEX.

\section{METHODS}

\section{Cells culture and experimental groups}

A549 cells (From Chinese Academy of Sciences cell bank)were cultured in F12K medium ,containing 10\% fetal bovine serum (the United States Gibco company). The cells were randomly divided into 4 groups $(n=10)$ :Normoxic group(N group):cultured in F12K without FBS for 30h;DEX group(D group):incubated with serum-free F12K medium containing DEX(1 nM)(Jiangsu Hengrui Medicine C, Ltd)for $30 \mathrm{~h} ; \mathrm{H} / \mathrm{R}$ injury group(H group): incubated with OGD solution for $6 \mathrm{~h}$ hypoxia, then cultured in serum-free $\mathrm{F} 12 \mathrm{~K}$ medium, reoxygenation for 24h;H/R+DEX group(HD group):hypoxia for $6 \mathrm{~h}$,reoxygenation for $24 \mathrm{~h}$,added DEX $(1 \mathrm{nM})$ to the culture medium at the beginning of hypoxia[7,8]..

\section{Setting Up H/R Models of A549 Cells}

According to the literature, H/R injury model of A549 was established [9,10].A549 cells in logarithmic growth phase were starved for $24 \mathrm{~h}$,Then cells were cultured with sugar-free OGD solution, hypoxia for $6 \mathrm{~h}$. The culture medium was replaced with serum-free $\mathrm{F} 12 \mathrm{~K}$ medium, reoxygenation for $24 \mathrm{~h}$.This is the establishment of H/R injury mode for A549 cells.

\section{Observing for morphological changes of A549 under the inverted microscope}

After the end of modeling, observe morphological changes of A549 Cells under the inverted microscope.

\section{Cell Viability assay(CCK-8)}

Cell viability was detected by Cell Counting Kit-8(CCK-8)(From Tongren Company, Japan ). A549 cells in the logarithmic growth phase were seeded in 96-well plate ISSN: 2250-1177 at a density of $1 \sim 5 * 10^{4}$ cells/well, cultured for $24 \sim 48 \mathrm{~h}$. Preparation of CCK-8 mixture: each well need $10 \mu \mathrm{l} \mathrm{CCK-8}$ and $100 \mu \mathrm{F} 12 \mathrm{~K}$ medium. After incubation in normoxia for $30 \mathrm{~min}$, the OD value was measured at $450 \mathrm{~nm}$ with a microplate reader.

\section{TUNEL}

TUNEL kit was purchased from Roche, Switzerland, DAB color kit $(20 \times)$ purchased from Beijing Zhong Jin Jinqiao Biotechnology Co, Ltd. Follow the instructions of TUNEL kit, perform tests. Positive cells are apoptotic cells, with brown particles in the nucleus. Each group was observed at least 5 visual fields and the number of positive cells in 100 cells in each field of view was counted, the apoptotic index is AI.

\section{Western blot analysis}

Extract proteins, quantified by the BCA kit (purchased from the China Biyun Biotechnology Research Institute).After denaturation, proteins were separated by SDS-PAGE and blocked with $5 \%$ skim milk solution, overnight incubation at $4^{\circ} \mathrm{C}$ with the appropriate antibody( Cell Signaling Technology company, US).Next day, combined with the secondary antibodies, incubation at room temperature for 1h. Add luminescent liquid, proteins were scanned by exposure meter. Densitometry was performed by Quantity One analysis software. The ratio of the accumulated light density (IOD) of the target protein band and the internal reference band (GAPDH) was the relative index of the protein expression level.

\section{Real -time PCR assay}

The total RNA was extracted by Trizol ( Life Technologies, USA) and The cDNA was synthetized by the RT-PCR kit (Fermentas, USA).PCR reaction conditions: JNK: initial denaturation, $94^{\circ} \mathrm{C}, 3 \mathrm{~min}$; denaturation, $94^{\circ} \mathrm{C}, 30 \mathrm{sec}$; annealing, $5^{\circ} \mathrm{C}, 30 \mathrm{sec}$; extended, $72^{\circ} \mathrm{C}, 1 \mathrm{~min}$,

cycle 38 times.GRP78/CHOP/Caspase-12/GAPDH: initial denaturation, $94^{\circ} \mathrm{C}$; denaturation, $94^{\circ} \mathrm{C}, 30 \mathrm{sec}$; annealing, $59^{\circ} \mathrm{C} / 52^{\circ} \mathrm{C} / 53^{\circ} \mathrm{C} / 54^{\circ} \mathrm{C}, 30$ sec; extended, $72^{\circ} \mathrm{C}, 1 \mathrm{~min} ; \mathrm{l}$ ast extended, $72^{\circ} \mathrm{C}, 5 \mathrm{~min}$. Respectively, 33 cycles. All primers were synthesized from Shanghai Jierui Bio engineering Co, Ltd. The PCR primer sequences were:GRP78: forward:5'-GTC CTA TGT CGC CTT CAC TCC-3';reverse:5'-AAA TGT CTT TGT TTG CCC ACC-3',and the length of amplification was 232bp.Caspase-12: forward:5'-AGC ACC AGT CCT CAG ACA GCA-3';reverse:5-GTG AAC CAA ACA ATC CCA GCA-3',220bp.JNK:forward:5'-CAT GGG CTA CAA GGA AAA 
CG -3';reverse:5'-GGA AAA GGA CAT CAG GGA

AGA-3',245bp.CHOP forward:5'-CCA CTC TTG ACC CTG CTT CTC-3';reverse:5'-CTA GCT GTG CCA CTT TCC TTT-3',246bp.GAPDH:forward:5'-ATC CCA TCA CCA TCT TCC AG-3';reverse:5'-TTG AGG CTG TTG TCA TAC TTC T-3',220bp.Then, electrophoresed with $1.5 \%$ agarose gel,100-120V,110mA,40min.and photographed with a fluorescent chemiluminescence imaging system, the image gray value was analyzed by the Quantity One software, and the expression levels was the IOD ratio of targeted mRNA and GAPDH mRNA.

\section{Caspase-3 activity assay}

Collected samples, prepare the caspase-3 activity assay kit (purchased from biyuntian biotechnology research institute, China).The absorbance (A) of pNA catalyzed by caspase-3 was $A$ of the sample minus A of the blank control. And then the pNA content in the sample can be calculated by the standard curve.

\section{Statistical analysis}

SPSS17.0 (SPSS Inc., US)was used for analysis. All metrological data were expressed as " $\bar{x} \pm s$ ”. The variance homogeneity test was used to compare the mean of samples in all groups, and one-way ANOVA was used in one group. If passed the variance homogeneity test, comparison of two pairs was performed by LSD, otherwise Dunnet't3 test. Bivariate correlation analysis was performed using the Pearson correlation analysis of the Bivariate process. $P<0.05$ was considered statistically significant.

\section{RESULT}

\section{Observing for morphological changes of A549 by the inverted microscope}

As shown in Fig.1,cells were the shuttle type, adherently growth in $\mathrm{N}$ group and D group. Nucleus were intact, ovoid, nucleolus clear, complete nuclear membrane(Fig.1A and B).Adherent cells was significantly reduced in $\mathrm{H}$ group, intercellular space increased, with changed shape, grow branches and polygonal. Some cells happened fusion phenomenon, nuclear condensation. Many cell debris and dead cells were seen (Fig.1C).Compared with the H group, the number of adherent cells in the HD group was relatively bigger, and cell debris and dead cells smaller (Fig.1D).
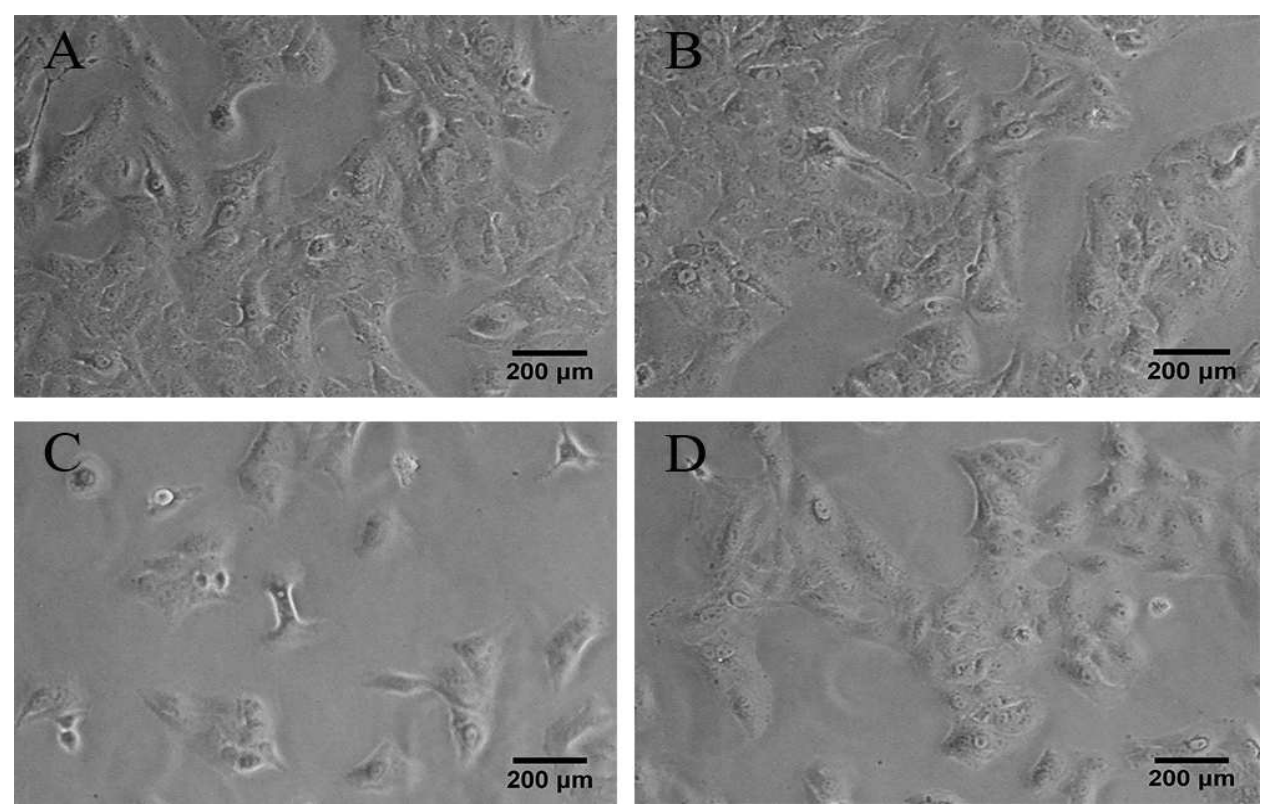

Fig.1. Microscopic growth of cells in each group

A:N group; B: D group; C: H group; D: HD group. 


\section{Cell Viability assay (CCK-8)}

Compared with $\mathrm{N}$ group, there was no significant difference in the OD value of $\mathrm{D}$ group $(P>0.05)$, OD value of $\mathrm{H}$ group decreased significantly $(P<0.01)$.Compared with $\mathrm{H}$ group, the OD value of HD group was increased, the difference was statistically significant $(P<0.01)$ (Fig.2).

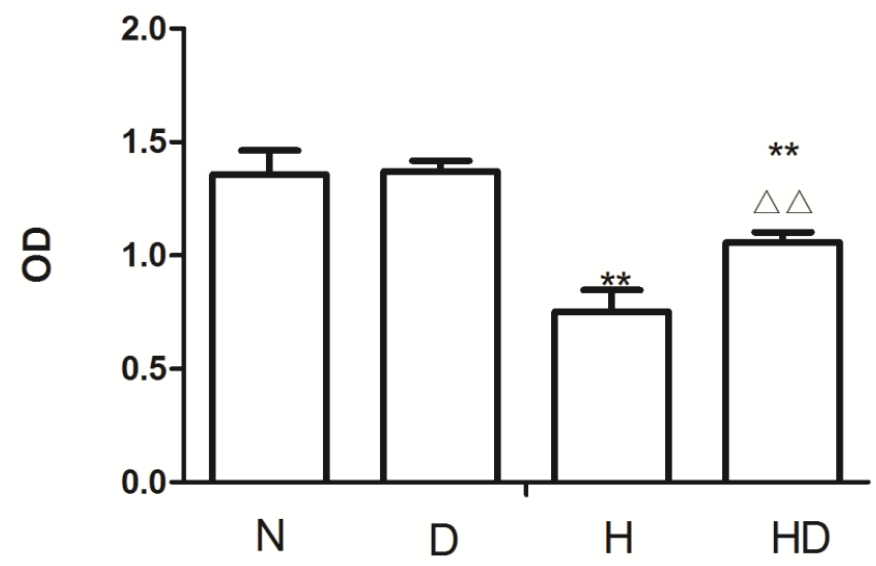

Fig.2. The expression change of OD value in all groups by CCK-8 method

$$
{ }^{* *} P<0.01 \text { vs } \mathrm{N} \text { group; } \triangle \triangle P<0.01 \text { vs } \mathrm{H} \text { group }
$$

\section{TUNEL}

The results showed that the $\mathrm{AI}$ value of $\mathrm{D}$ group was significantly higher than $\mathrm{N}$ group $(P>0.05)$ (Fig.3A and B).Apoptotic cells increased significantly $(P<0.01)$.Compared with $\mathrm{H}$ group, the $\mathrm{AI}$ value of $\mathrm{HD}$ group decreased significantly, the number of apoptotic cells decreased, the difference was statistically $\operatorname{significant}(P<0.01)$ (Fig.3C and D).
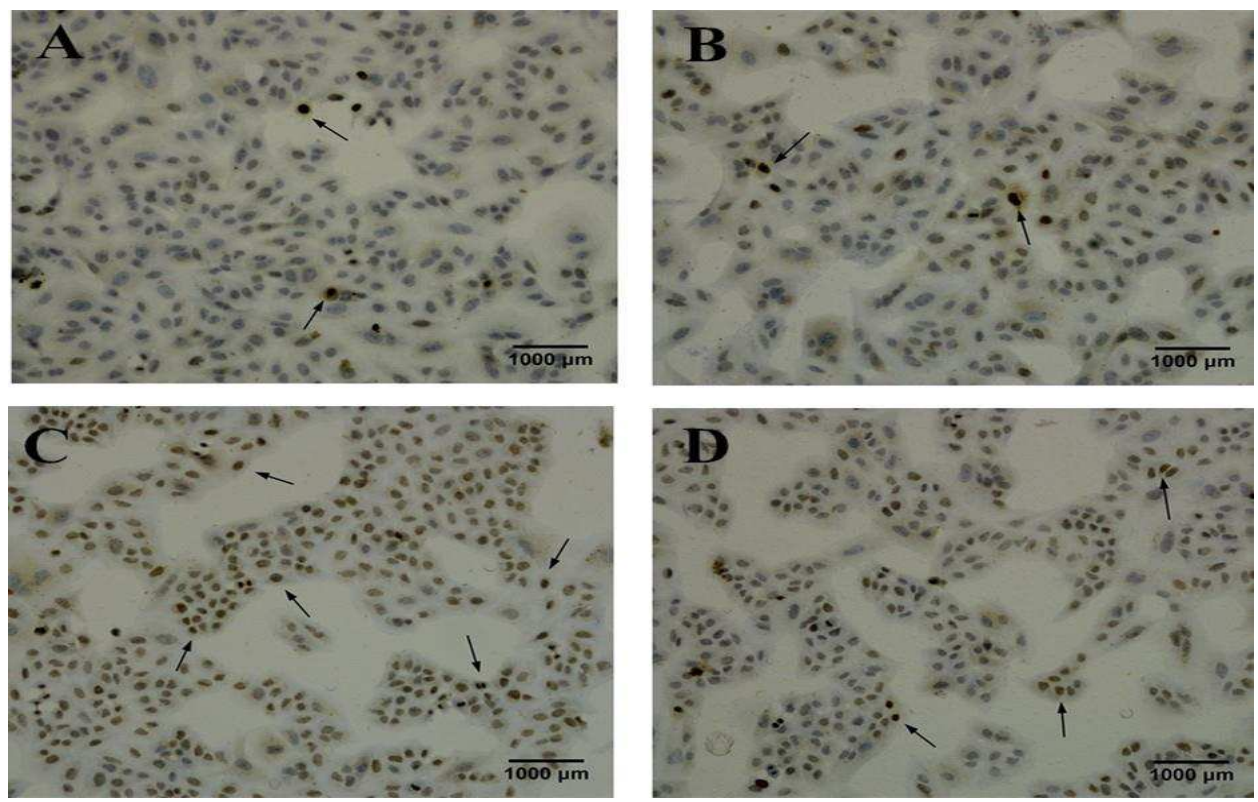

Fig. 3. Apoptosis of each group

A: N group; B: D group; C: H group; D: HD group 


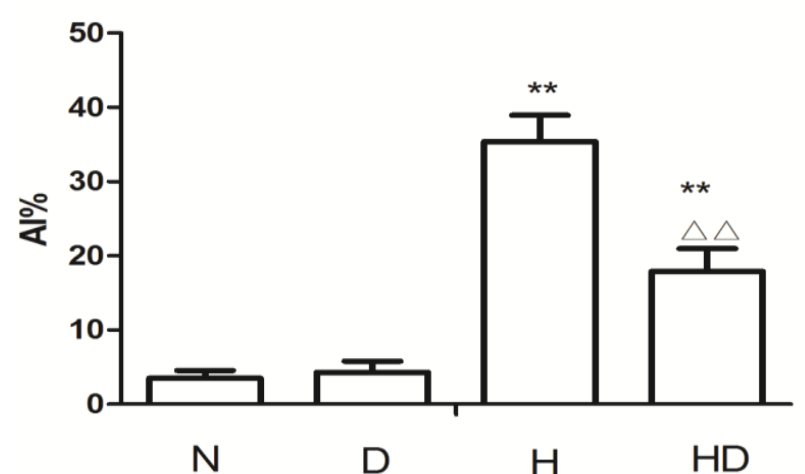

Fig.4. The expression change of AI value in all groups by TUNEL method

${ }^{* *} P<0.01$ vs $\mathrm{N}$ group; $\triangle \triangle P<0.01$ vs $\mathrm{H}$ group

\section{Western Bolt}

As shown in Fig.5-9, the levels of GRP78,CHOP,Caspase-12, p-JNK and Caspase-3 protein in D group were not significantly different from those in $\mathrm{N}$ group $(P>0.05)$. The levels ofGRP78, CHOP, caspase-12, p-JNK and the expression of caspase- 3 protein were significantly increased in $\mathrm{H}$ group $(P<0.01)$. Compared with $\mathrm{H}$ group, the expression of CHOP, caspase-12, p-JNK and caspase-3 protein in HD group was significantly lower $(P<0.01)$.
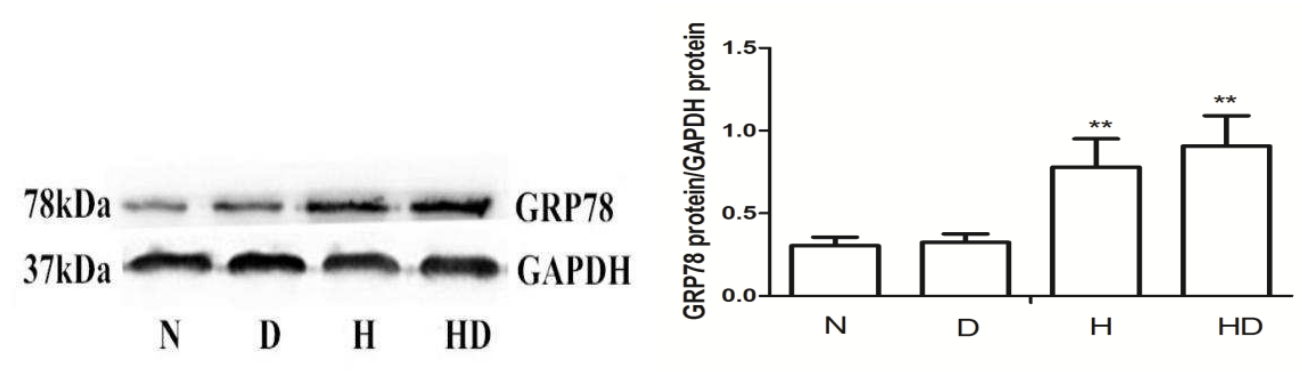

Fig.5. The expression level of GRP78 protein in all groups.

${ }^{* *} P<0.01$ vs $\mathrm{N}$ group; $\triangle \triangle P<0.01$ vs $\mathrm{H}$ group
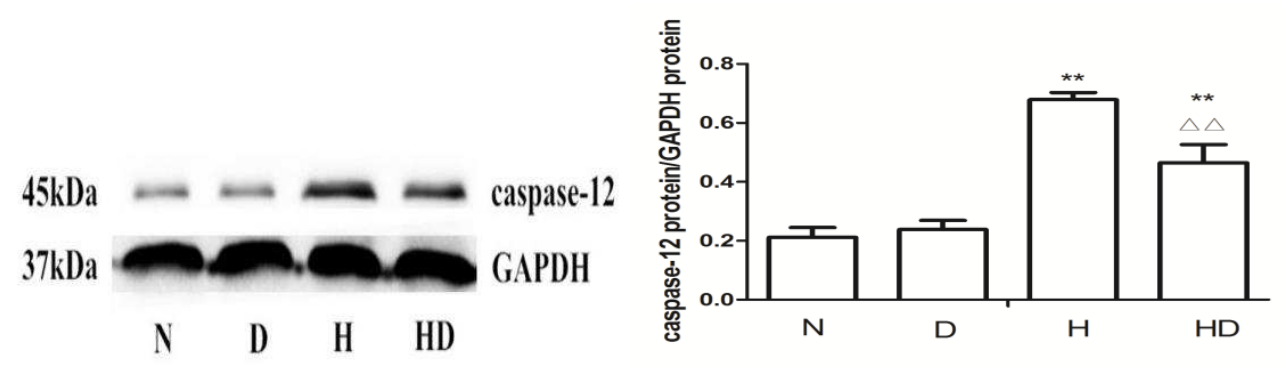

Fig.6. The expression level of caspase-12 protein in all groups

${ }^{* *} P<0.01$ vs $\mathrm{N}$ group; $\triangle \triangle P<0.01$ vs $\mathrm{H}$ group

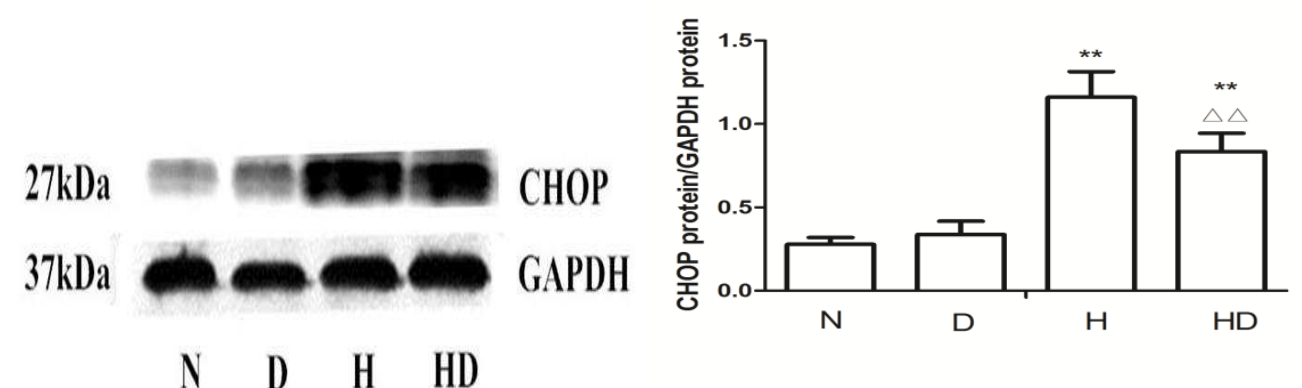

Fig.7. The expression level of CHOP protein in all groups.

${ }^{* *} P<0.01$ vs $\mathrm{N}$ group; $\triangle \triangle P<0.01$ vs $\mathrm{H}$ group 


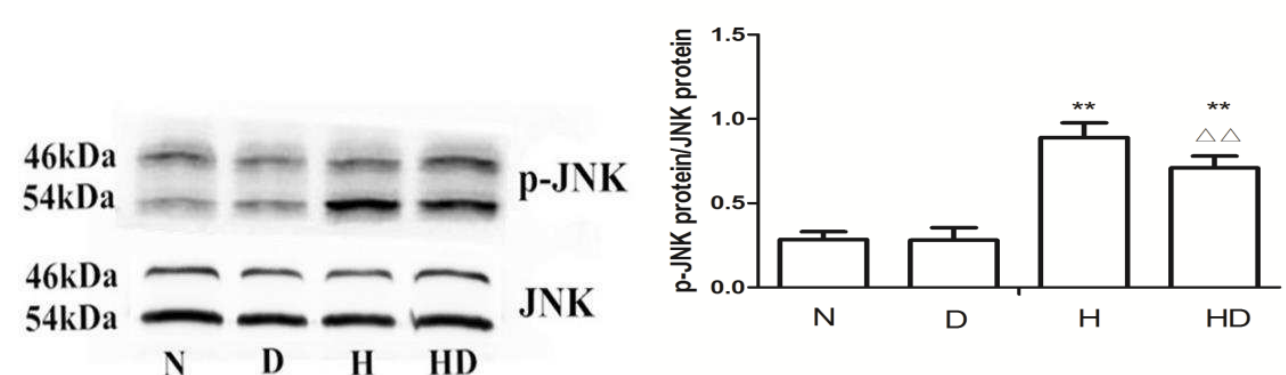

Fig.8. The expression level of p-JNK protein in all groups.

${ }^{* *} P<0.01$ vs $\mathrm{N}$ group; $\triangle \triangle P<0.01$ vs $\mathrm{H}$ group

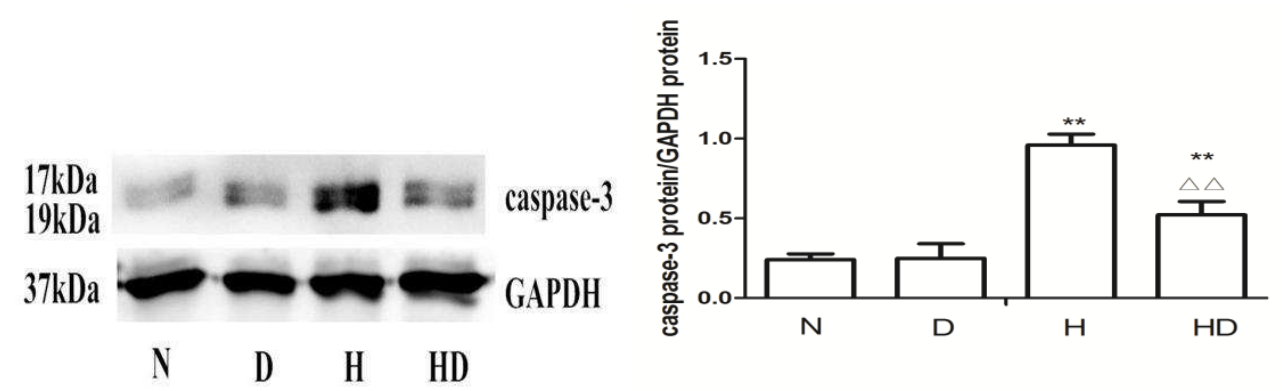

Fig.9. The expression level of caspase-3 protein in all groups.

${ }^{* *} P<0.01$ vs $\mathrm{N}$ group; $\triangle \triangle P<0.01$ vs $\mathrm{H}$ group

\section{RT-PCR}

Compared with N group, the levels of GRP78, CHOP, Caspase-12 and JNK mRNA in D group were not significantly different $(P>0.05)$.The expression of GRP78,CHOP, Caspase-12 and JNK mRNA in H group were significantly increased $(P<0.01)$. Compared with $\mathrm{H}$ group, the expression of CHOP, caspase-12 and JNK mRNA was significantly decreased in the HD group $(P<0.01$, Fig. 10-13)
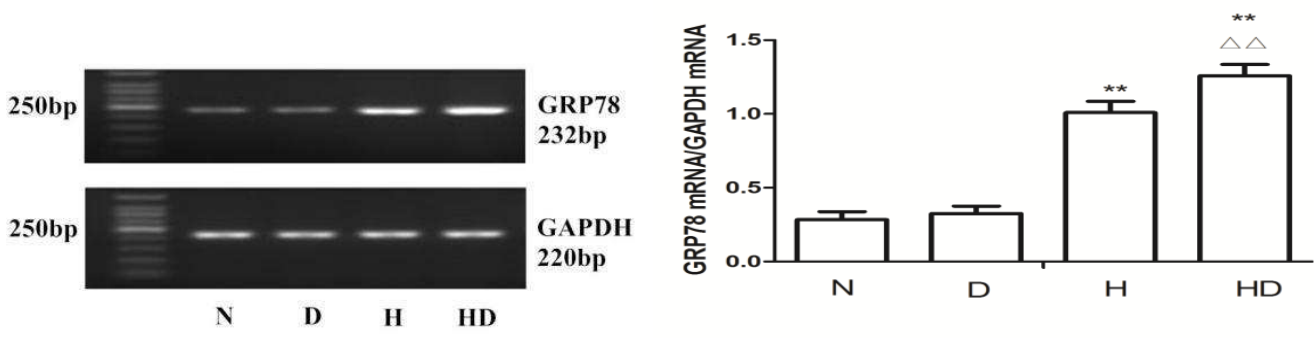

Fig.10. The expression level of GRP78 mRNA in all groups.

${ }^{* *} P<0.01$ vs $\mathrm{N}$ group; $\triangle \triangle P<0.01$ vs $\mathrm{H}$ group
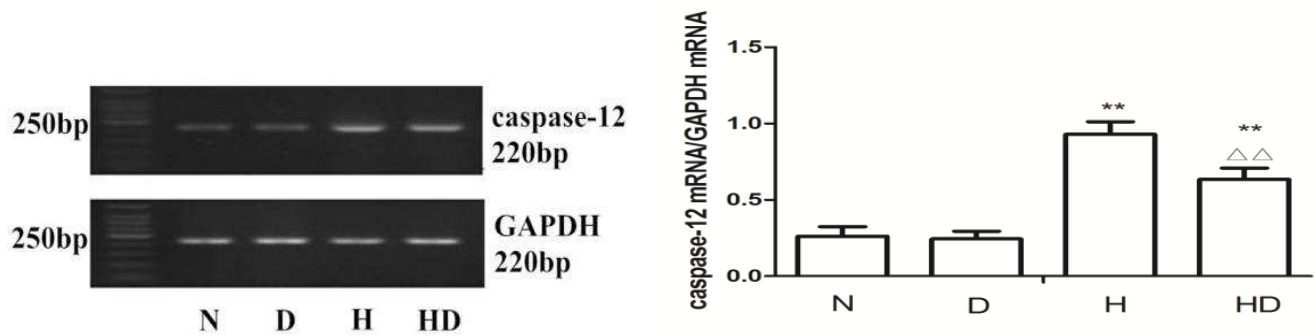

Fig.11. The expression level of caspase-12 mRNA in all groups.

${ }^{* *} P<0.01$ vs $\mathrm{N}$ group; $\triangle \triangle P<0.01$ vs $\mathrm{H}$ group 

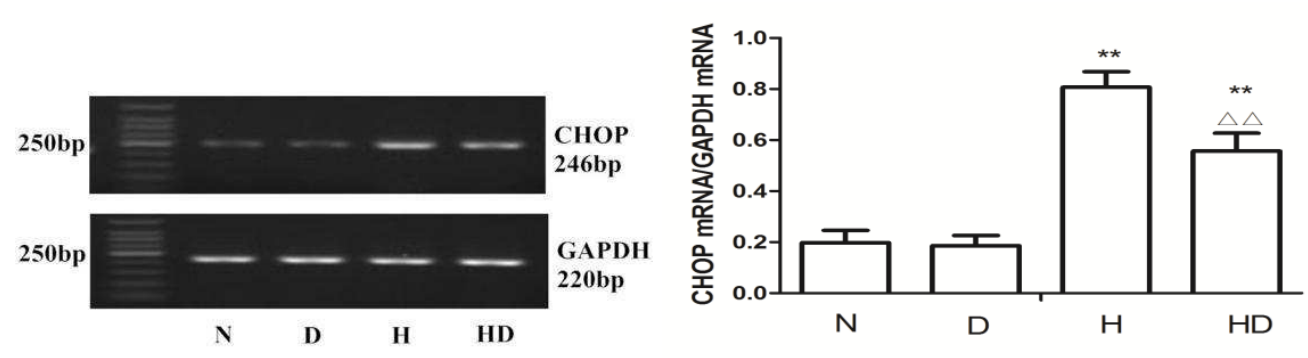

Fig.12. The expression level of CHOP mRNA in all groups.

${ }^{* *} P<0.01$ vs $\mathrm{N}$ group; $\triangle \triangle P<0.01$ vs $\mathrm{H}$ group
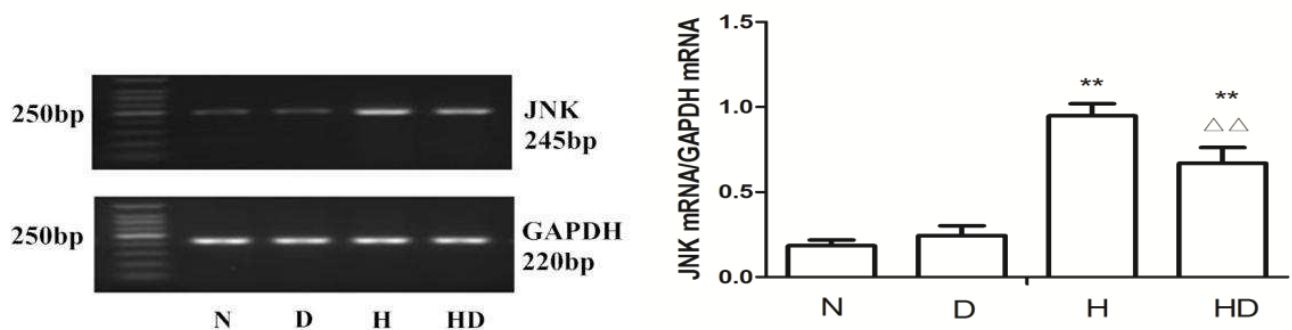

Fig.13. The expression level of JNK mRNA in all groups.

${ }^{* *} P<0.01$ vs $\mathrm{N}$ group; $\triangle \triangle P<0.01$ vs $\mathrm{H}$ group

\section{Caspase- 3 activity test}

Compared with $\mathrm{N}$ group, the activity of caspase- 3 in D group was not significantly different $(P>0.05)$, the activity of caspase-3 in $\mathrm{H}$ group was significantly higher $(P<0.01)$. Compared with $\mathrm{H}$ group, the activity of caspase- 3 was significantly decreased in HD group $(P<0.01$, Fig 14$)$.

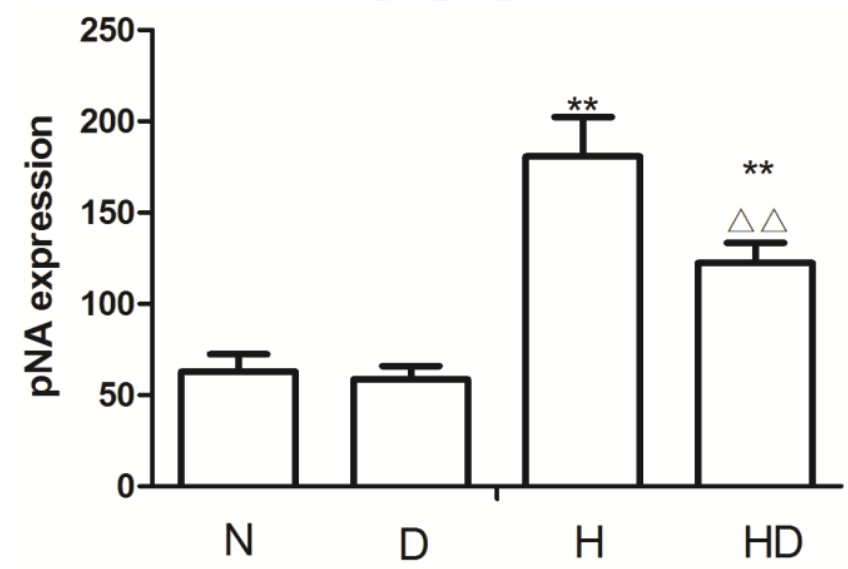

Fig.14. The expression change of pNA value in all groups ${ }^{* *} P<0.01$ vs $\mathrm{N}$ group; $\triangle \triangle P<0.01$ vs $\mathrm{H}$ group

\section{DISCUSSION}

Endoplasmic reticulum stress (ERS)-mediated apoptotic pathway is a commonly recognized mechanism of apoptosis. The energy metabolism, oxidative stress, calcium overload and inflammatory response in the process of I/R can break the homeostasis and induce ERS. Moderate ERS is beneficial to restore the homeostasis and maintain survival, but when the ERS continues to be too strong, the protective mechanism cannot compete with the injury, will eventually lead to apoptosis, further aggravating LIRI. At present, ERS-induced apoptosis is mainly associated with expression change of CHOP and GRP78, activation of caspase-12 and JNK[11-14].DEX is a highly selective $\alpha_{2}$ adrenergic receptor agonist. A large number of studies ${ }^{[15,16]}$ have shown that DEX plays an important role in weakening oxidative stress, alleviating lung injury and inhibiting apoptosis of lung cells. The results of this study showed that DEX may reduce the $\mathrm{H}$ 
/ R injury and the apoptosis of A549 cells by inhibiting excessive ERS. This study provided additional evidence for the application of clinical drugs, found new therapeutic targets for LIRI.

\section{Conflict-of-Interest Notification: None.}

\section{ACKNOWLEDGMENT}

This work was supported by the Public Technology Research Project (No:2013C33168) and The Xinmiao Telent Project of Zhejiang Province, China(No:2014R413043) ,as well as the Public Science and Technology Project of Wenzhou Municipality, Zhejiang Province, China(No:Y20140652);Yin Zhi project, Wenzhou, Zhejiang Province, China ( NO: 604090355/ 031; NO:604090355/032).

\section{REFERENCES}

1. Junhui Zhou, Liangrong Wang, Maolin Hao. Effects of small interfering RNA on apoptosis and CCAAT / enhancer binding protein homologous protein in lung ischemia / reperfusion injury in mice. Chinese Journal of Experimental Surgery. 2013; 30:1608-11.

2. Maolin HAO, Shan ZHAO, Haie CHEN. Effect of JNK gene on lung injury induced by ischemic reperfusion in siRNA under over expressing endoplasmic reticulum. Chinese Journal of Applied Physiology.2014; 30:5-10.

3. Junhui Zhou, Dan Chen, Haie Chen. Effects of caspase-12-siRNA pretreatment on lung ischemia-reperfusion injury in mice. Chinese Journal of Anesthesiology. 2014; 34:105-107.

4. Kucuk A, Yaylak F, Cavunt-Bayraktar A. The protective effects of dexmedetomidine on hepatic ischemia reperfusion injury.Bratisl Lek Listy. 2014; 15: 680-684.

5. Guo Changman, Chen Dan, Song Dong. Protective effects of dexmedetomidine on lung ischemia-reperfusion injury in mice. Chinese Journal of Clinical Pharmacology and Therapeutics.2016; 21:145 -149.

6. Chen Dan, Song Dong, Ye Yuzhu. Deemethamidine by affecting the CHOP apoptotic pathway to reduce ischemia / reperfusion lung injury. Chinese Journal of Pathophysiology.2015; 31:1093-98.

7. Jian Cui, Hailin Zhao, Chunyan Wang. Dexmedetomidine attenuates oxidative stress induced lung alveolar epithelial cell apoptosis in vitro. Oxidative Medicine and Cellular Longevity.
2015; 2015:1-11

8. Chenfang Luo, Dongdong Yuan, Weifeng Yao. Dexmedetomidine protects against apoptosis induced by hypoxia/reoxygenation through the inhibition of gap junctions in NRK-52E cells. Life Sciences .2015; 122:72-77.

9. Wang Wang, Lingyun Jia, Tengke Wang. Endogenous calcitonin gene-related peptide protects human alveolar epithelial cells through protein kinase $\mathrm{C}$ and heat shock protein. J Biol Chem .2005; 280:20325-30.

10. Lingyun Jia, Mingjiang $\mathrm{Xu}$, Wei Zhen. Novel anti-oxidative role of calreticulin in protecting A549 human type II alveolar epithelial cells against hypoxic injury. Am J Physiol Cell Physiol. 2008; 294:47-55.

11. Kim MH, Aydemir TB, Cousins RJ. Dietary zinc regulates apoptosis through the p-elF $2 \alpha /$ ATF4/CHOP Pathway during Pharmacologically Induced Endoplasmic Reticulum Stress in Livers of Mice.J Nutr .2016; 146:2180-86.

12. Lakshmanan AP, Thandavarayan RA, Palaniyandi SS. Modulation of AT-1R/ CHOP-JNK-Caspase12 pathway by olmesartan treatment attenuates ER stress-induced renal apoptosis in streptozotocin-induced diabetic mice. Eur J Pharm Sci.2011; 44:627-634.

13. $\mathrm{Xu}$ J, Qin $\mathrm{X}$, Cai $\mathrm{X}$. Mitochondrial JNK activation triggers autophagy and apoptosis and aggravates myocardial injury following ischemia/reperfusion. Biochim Biophys Acta.2015; 1852:262-270.

14. Zhang XY, Zhang TT, Song DD. Endoplasmic reticulum chaperone GRP78 is involved in autophagy activation induced by ischemic preconditioning in neural cells . Mol Brain 2015; 8:20.

15. Jiang YX, Dai ZL, Zhang XP. Dexmedetomidine alleviates pulmonary edema by upregulating AQP1 and AQP5 expression in rats with acute lung injury induced by lipopolysaccharide. Huazhong Univ Sci Technolog Med Sci.2015; 35:684 -688.

16. Cui J, Zhao H, Yi B,et al. Dexmedetomidine Attenuates Bilirubin-Induced Lung Alveolar Epithelial Cell Death In Vitro and In Vivo.Crit Care Med. 2015; 43:356-368. 